\title{
The Difference of Dopamine Transporter and Serotonin Transporter Level Between Addicted and Non-Addicted Internet User Experiencing Stress in Senior High School Students in Padang, Indonesia
}

\author{
Yaslinda Yaunin ${ }^{1}$, Eriyati Darwin ${ }^{2}$, Yanwirasti ${ }^{3}$, A.E.Nurdin ${ }^{4}$, Husna Yetti ${ }^{5}$, \\ Rini G.Liza ${ }^{6}$ \\ \{linda_yns@yahoo.co.id $\left.{ }^{1}\right\}$ \\ Psychiatry Departement of Medical Faculty, Andalas University 1,4,6 \\ Biomedical Laboratory of Medical Faculty, Andalas University ${ }^{2,3}$ \\ Public Health Departement of Medical Faculty, Andalas University ${ }^{5}$
}

\begin{abstract}
Stress can be a disorder or may cause physiological dysfunction and psychological disorder. The Internet has been using widely. Despite its positive effect, it also has negative effect, particularly regarding to stress among student. The aimed of the study was to investigate the difference between Dopamine Transporter (DAT) and Serotonin Transporter (5HTT) level between stress experienced by addicted and nonaddicted internet users and to investigate the variable influenced internet addiction. The method used a cross-sectional comparative study; the stress level was assessed by using Depression Anxiety and Stress Scale, Internet addiction using Kimberly Young Internet Addiction test. Enzyme-Linked Immunosorbent Assay (ELISA) was used to determined peripheral blood DAT and 5HTT levels from the students who diagnosed stress. 681 students have participated, the prevalence of stress among senior high school students was $292(42,88 \%)$ and students who were not experiencing stress $289(57,12 \%)$. The sample of the study was selected 79 students experienced stress and internet addicted, and 68 students experienced stress, but non-internet addicted users. There is a significant difference (p-value: 0,001) DAT and 5HTT level in peripheral blood serum between this two group. DAT levels showed a high relationship between student experiencing stress and internet addiction. It confirmed there was dysfunction of the DAT and 5HTT in internet addicted student. The peripheral blood DAT and 5HTT level remain high in internet-addicted student and dopamine transporter have an important role in internet addiction.
\end{abstract}

Keywords: 5HTT, DAT, Internet Addiction, Stress.

\section{Introduction}

Stress can be a disorder or may cause physiological dysfunction and psychological disorder. Yusoff (2010) studied on 100 students of Senior high school in Kota Bharu (Kelantan), Malaysia found the prevalence of stress was $26.1 \%$, and this figure was relatively high compared to a normal population which is less than $10 \%[1]$. Kinantie et al (2013) conducted research on Senior high school in Bandung to 192 students obtained $15.10 \%$ was mild stress, 50\% was moderate stress, $30.20 \%$ was severe stress and $0.52 \%$ was very severe stress[2]. Childhood 
stress, psychosomatic and emotional symptoms in school-age children are currently a problem in the field of psychiatry.

The high prevalence of psychosomatic symptoms indicates that most children have predisposition psychosomatic disorders related to emotional factors and behavioral disorders when in stressful environments [3] The Internet is a new tool that has developed into an important part of daily life throughout the world and has increased use, especially among young people. Although this tool is considered a broad benefit, psychologists and educators have been aware of the negative impact of internet use on physical and psychological issues [4]. In recent years more and more are interested in studying the negative effects of the internet. No doubt some internet users have caused behavioral problems [5],[6]. Other researchers state that in addition to the effects on internet addiction also affects physical health (sleep disturbances, eating time) and mental health.

Communication via the internet is considered important for adolescents who cannot socialize as a substitute for friends in the real world, Ayas and Horzum Research on 292 students in Trabzon (Turkey) in 2009-2010 found an Internet addiction relationship with depression, loneliness, and self-esteem [7]. After considering some circumstances, the World Health Organization (WHO) included game addiction or "game disorder" as a mental disorder. WHO added addiction to the Classification of Disease XI game (ICD-XI) into a "due to addictive behavior" or disorder caused by habit or addiction.[8] A total of 552 students in India were included in Yadav et al. 's study: Internet addiction was measured by the "Young Internet Addiction Test" questionnaire and measuring stress, depression with the "Depression, Anxiety and Stress Scale (DASS) questionnaire A relationship was found that scores internet addiction and depression, and stress scores [9]. Pontes et al. (2014) conducted a study of 131 Portuguese children and adolescents in Lisbon about the relationship between internet addiction and loneliness. The results of his study found a significant relationship between loneliness and internet addiction [10].

Dopamine Transporter (DAT) is a protein that is located at the terminal presynaptic and is responsible for activating the re-uptake of dopamine into presynaptic neurons and plays an important role in regulating dopamine levels. Previous researchers have proven that changes in DAT concentration in the striatum occur in chronic substance addicts. In recent years DAT has been used as an important clinical guide in determining changes in brain structure in patients with substance addiction [11], [12]. Hou et al. (2012) randomly examined the coming Shenzhen University Hospital, they spent more than 8 hours/day in front of the monitor screen, mostly for chatting, playing online games, watching adult movies or online pornography. Compared to controls ( 9 people) who rarely use the internet or occasionally and not more than 5 hours/day and do not meet the criteria of internet addiction according to Kimberly Young which has been translated into Chinese. The results showed that the expression level of DAT in the Striatum region showed a significant decrease in the disorder group[12].

Changes in the serotonin system (5HT) have also been investigated in the relationship between the nature of aggression and disorders of addiction. Lee et al. (2008) proving that one homozygous short allele of serotonin transporter gene (5HTTLPR) is more frequent in excessive internet users. They also stated on internet addiction disorders, as well as other addictive behavioral disorders research. Because it is reasonable to say that internet addiction is also related to serotonin system dysfunction as a neurobiological aspect [13]

This study aims to investigate the difference of Dopamine Transporter (DAT) and Serotonin Transporter or 5 hydroxytryptamine Transporter (5HTT) level between stress and internet addiction students and stress not internet addiction students, also to find the most influential variable that make stress students will be internet addiction. 


\section{Materials and Methods}

Before the study was conducted, an "Ethical Clearance" was requested from the Ethics Commission Research of Medical Faculty, Andalas University. Sampling was carried out by random sampling in State High Schools in the City of Padang starting from the State High School the lowest graduation on the previous national exams. The sample was taken from February until Mei 2016. Given the questionnaire of the Depression Anxiety Stress Scale (DASS) to find that students who experienced stress and Kymberly Young internet addiction questionnaire was given to determine students who were internet addicted and non-internet addicted[14]. Peripheral blood samples were taken to measure the levels of Dopamine Transporter (DAT) and Serotonin Transporter or 5 hydroxytryptamine Transporter (5HTT) and then by using the Enzyme-Linked Immunosorbent Assay (ELISA) in the Biomedical Laboratory of the Medical Faculty, Andalas Padang University.

Inclusion criteria: the second year student in senior high school in Padang, and willing to participate in this study.

Exclusion Criteria: having a fever or disease that requires treatment, female students are menstruating, already having severe emotional distress before (such as: depression or learning disorder in need of treatment by doctors and / or psychologists), being or just experiencing a severe life trauma such as: death of a person,losing valuable items.

\section{Results}

A total of 681 students participated at the beginning of the study. From the results of the DASS questionnaire, it was found that students who experienced stress were $292(42.88 \%)$ and students who did not experience stress were 389 (57.12\%). All 292 stressed students were the population of this study, 121 male $(41.4 \%)$ and 171 female $(58.6 \%)$. By considering the inclusion and exclusion criteria in the population, the research sample is determined. Next, the research sample was given internet addiction questionnaire from Kimberly Young to determine the students who are stressed and addicted to the Internet. The results were obtained as much as 79 students (35 males, 44 females) are stress and internet addiction, 68 students(32 males, 36 females) stress and non-internet addiction.

Table 1. Media Were Used For Internet Among Stress Students.

\begin{tabular}{lllll}
\hline \multirow{2}{*}{ Media Were Used For Internet } & \multicolumn{2}{l}{ Internet Addiction } & \multicolumn{2}{l}{ Non Internet Addiction } \\
\cline { 2 - 5 } & $\mathrm{f}$ & $\%$ & $\mathrm{f}$ & $\%$ \\
\hline Cellphone & 70 & 88,61 & 60 & 88,24 \\
Internet Café & 7 & 8,86 & 7 & 10,29 \\
School Computer & 0 & 0 & 0 & 0 \\
House Computer & 2 & 2,53 & 1 & 1,47 \\
\hline Total & 79 & 100 & 68 & 100 \\
\hline
\end{tabular}

From table 1, it can be seen that the most frequent use of the internet for stressed and internet addicted students is $88,61 \%$ using Cellphone and also for stress students non-addicted to the internet $(88.24 \%)$. The cell phone is almost as a primary requirement for most people today, as well as for students in high school. Almost all high school students currently have a cell phone, 
so it is no wonder the most internet use is also via cellphones. Especially at this time some schools, restaurants or cafes, entertainment places have provided free internet services through wi-fi, making it easier to get internet access at low prices.

Table 2. The Most Important Goal of Internet Used Among Stress Students.

\begin{tabular}{|c|c|c|c|c|}
\hline \multirow{2}{*}{ Most Importance Used } & \multicolumn{2}{|c|}{ Internet Addiction } & \multicolumn{2}{|c|}{ Non-Internet Addiction } \\
\hline & $\mathrm{f}$ & $\%$ & $f$ & $\%$ \\
\hline $\begin{array}{l}\text { Social Media(Chatting, Facebook, WA, } \\
\text { Twitter, etc) }\end{array}$ & 51 & 64,56 & 33 & 48,83 \\
\hline Game Online & 13 & 16,46 & 6 & 8,82 \\
\hline Email & 0 & 0 & 0 & 0 \\
\hline Watching Movies & 3 & 3,80 & 5 & 7,35 \\
\hline Gambling Online & 0 & 0 & 1 & 1,47 \\
\hline For Study & 9 & 11,39 & 19 & 27,95 \\
\hline Health Information & 1 & 1,26 & 2 & 2,94 \\
\hline Others & 2 & 2,53 & 2 & 2,94 \\
\hline Total & 79 & 100 & 68 & 100 \\
\hline
\end{tabular}

In table 2 it can be seen that internet used were most often for stressed and internet addicted students is $64.56 \%$ for the benefit of social media and second is $16,46 \%$ for games online while stressed students are non-internet addicted $48.83 \%$ also for the benefit of social media and second $27.95 \%$ to seek lessons. In this study, it turns out that the use of internet dominated for the benefit of social mediabecause at this time the easiest and quickest entertainment obtained is also through cellphones connected to the internet with a variety of programs and to communicate with friends or family is very easy to do with cellphones.

Table 3. The Difference in DAT Levels between Stress and Internet Addiction Students and Stress NonInternet Addiction Students.

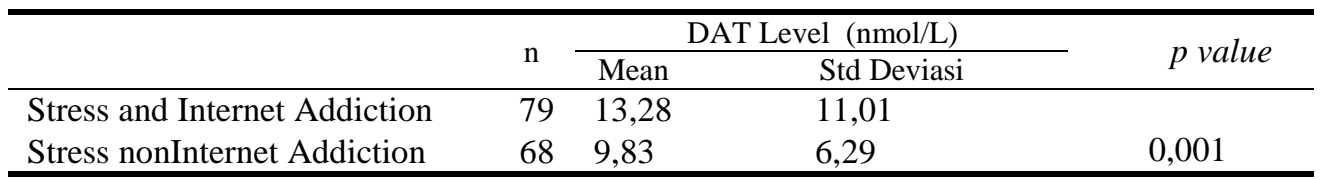

In table 3, the results of the average Dopamine Transporter in stressed and internet addicted students were higher, namely $13.28 \pm 11.01 \mathrm{nmol} / \mathrm{L}$ compared to stressed students who were non-internet addicted with an average Dopamine Transporter of $9.83 \pm 6.29 \mathrm{mmol} / \mathrm{L}$. Statistical analysis showed that $\mathrm{p}$-value $0.001(\mathrm{p}<00.5)$ it means that in this study there were significant differences in Dopamine Transporter (DAT) levels in peripheral blood between Stressful Students with Internet Addiction and Stress Students who did nonInternet Addiction.

Table 4. The Difference in 5HTT Levels between Stress and Internet Addiction Students and Stress NonInternet Addiction Students.

\begin{tabular}{lllll}
\hline & & \multicolumn{2}{c}{ 5 HTT Level (nmol/L) } & \multirow{2}{*}{ p value } \\
\cline { 3 - 4 } & $n$ & Mean & Std Deviasi & \\
\hline Stress and Internet Addiction & 79 & 18,37 & 19,61 & 0,001 \\
Stress nonInternet Addiction & 68 & 12,96 & 12,08 & \\
\hline
\end{tabular}


In table 4.the average value of Serotonin Transporter in stressed and internet addicted students were higher namely 18,37 $\pm 19,61 \mathrm{nmol} / \mathrm{L}$ than stressed students are non-internet addicted with an average serotonin transporter 12,96 $\pm 12,08 \mathrm{nmol} / \mathrm{L}$. By the statistical analysis of this study showed that $\mathrm{p}$-value $0.001(\mathrm{p}<00.5)$ it means that in this study there were significant differences in Serotonin Transporter (SHTT) levels in peripheral blood between Stress Students Internet Addiction and Stress Students Non-Internet Addiction.

Table 5. Logistic Regression Analysis.

\begin{tabular}{|c|c|c|c|c|c|c|c|}
\hline & & B & S.E. & Wald & $\mathrm{df}$ & Sig. & $\operatorname{Exp}(B)$ \\
\hline Step 1(a) & DAT & ,768 & ,373 & 4,234 & 1 & ,040 & 2.156 \\
\hline 5HTT & & 029 &, 046 & ,411 & 1 &, 521 & 1,030 \\
\hline Constant & & 211,403 & 82,585 & 6,553 & 1 & ,010 & $6471 \mathrm{E}+091$, \\
\hline
\end{tabular}

a Variable(s) entered on step $1:$ DAT, 5HTT

From table 5 above, can see the Odd Ratio value (Exp B) on DAT is higher than SHTT, so that can say DAT has more influence on internet addiction on students who are as stressful.

\section{Discussion}

In this study found that the prevalence of stress in senior high school students was quite high (42.88\%), this result is higher than Yusoff's (2010) study 26,1\% of stressed students in Kota Bharu, Malaysia and Shibuya's research (2011) found $37 \%$ of children had psychosomatic symptoms at least once a week. It seems that there was an increase in the incidence of stress in children- teenagers. This situation must be monitor by parents and teachers, so the students do not fall in severe depressive. Mostly the main goal of internet using is for social media $(64,56 \%)$ and game on the line $(16,46 \%)$, this is in line with PriyankaYadav's(2013) study for social media goal $78,5 \%$ and game $40 \%$. In contrast toYajun Li study (2014) game $22,5 \%$ and communication with friends $13,5 \%$.

In this studyDopamin Transporter (DAT)was found to be significant differences between cases and controls, this is in line with Jovic J (2011) and Hou et al. (2012) that there was dysfunction of the dopaminergic system in people who addicted to the internet. Dopamine as neurotransmitter plays a role in regulating mood, emotions and motivation and reward processes (Young et al. 2011). In this study higher dopamine transporters in students who stressed and internet addicted than stressed students, not internet addicted; it means that dopamine levels were low in stressed and internet addicted students. The results of this study indicate a recurring tendency to use the internet until satisfaction and pleasure in the group of stress internet addicted students so that dopamine transporter decrease and free dopamine increase and also dopamine in the synaptic gap increases and binds to the receptors.

There is also a significant difference between cases and control in Serotonin Transporter or 5 hydroxytryptamine Transporter (5HTT) values, in line with Lee et al. (2012) reported there is serotonergic system dysfunction in internet addiction.

The serotonin system is involved in many psychiatric processes, especially related to mood, sleep, and psychosis..Serotonin serves as a control inhibitor to excessive aggressive impulses.

Changes in serotonin system (5HT) have also been investigated the relationship between the nature of aggression and internet addiction disorders. Patients who are characterized by aggressive impulses are associated with a reduced central serotonergic function in studies 
through metabolic monamine in cerebrospinal fluid. Lee et al. (2008) proved that short allele of serotonin transporter gene (5HTTLPR) is more frequent in excessive internet users. They also stated that there is a dysfunction of the serotonin system in internet addiction disorders, as well as other addictive behavioral disorders research. It is quite reasonable to say internet addiction is also related to serotonin system dysfunction as a neurobiological aspect (Hahn and Kim 2014).

In this study found that Odd Ratio (OR) value (Exp B) in Dopamine Transporter (DAT) higher than that of Serotonin Transporter or 5 hydroxytryptamine Transporter (5HTT), so it can be said that DAT has more influence on stress students to be internet addiction.

There are several limitations of this study in some samples that cannot represent all stress students and internet addiction in Padang. This study also not see the background and environmental life of students.

\section{Conclusions}

This study found that prevalence of stress among senior high school students in Padang, Indonesia was quite high $(42,88 \%)$ and there are significant differences of peripheral blood Dopamine Transporter (DAT)between stress and internet addicted students and students were stress and non-internet addicted. This study also found there are significant differences of peripheral blood level of Serotonin Transporter or 5 Hydroxy Tryptamine Transporter (5HTT)between stress and internet addiction students and stress non-internet addition students. There is a relationship between stress, dopamine transporter, serotonin transporter, and internet addiction. The logistic regression analysis found that the dopamine transporter levels were high relationship effect to make a stressed student becomes addicted to the internet.

In addition, further studies can be done to find several factors that make students stress and the differences of stress according to the Intelligence Question (IQ) also the using of counseling teacher at a school for the students who have problems. The next study of internet addiction among teenager in internet café can be done and find out environmental life of them.

\section{References}

[1] Yusoff, MSB.: Stress, Stressor, and Coping Strategies Among Secondary School Student in Malaysian Government Secondary School in Asian J PsychiatrVol 11 (2) July - December 2010, $1-15(2010)$

[2] Kinantie,OA, HernawatyT, Hiayati,NO.: Gambaran Tingkat Stres Siswa SMANBandung Kelas XII Menjelang Ujian Nasional 2012" FkepUnpad(2013)

[3] Shibuya I, Shinichiro N, Okamura H, Ozano S, Chiba H, Ohyat, Yamashita, et al.: High Correlation Between Salivary Cortisol Awakening Response and The Psychometric Profile of Healthy Children in Bio Psychososial Medicine 8:9(2014)

[4] Akin A., Iskender M.: Internet Addiction and Depression, Anxiety and Stress. International Online Journal of Educational Science 3(1), 138-148(2011)

[5] Fioravanti G., Dettore D., Casale S.: Adolescent Internet Addiction , Testing the Association Between Self Esteen, Perception of Internet Attributes, and Preference on Line Social Interactions in Cyberpsychology, Behavior, and Social Networking, Vol 15, Number 6 pp : 318 $323(2012)$

[6] Tsitsika A., Critselis E., Louizou A. et al.: Determinants of Internet Addiction among Adolescents A Case - Control Study, ScientificWorldJournal (2011) II, 866-874 (2011) 
[7] Ayas T., Horzum MB.:Relation Between Depression, Loneliness, Self Esteem and Internet Addiction. Education Spring Academic Journal Article, retrieved:www.questia.com/library/journal/IGI-357760558/ (2014)

[8] World Health Organization (WHO): https://sains.kompas.com/read/2018/06/19/192900123 2018

[9] Yadav P, Banwari G, Parmar C, Maniar R.: "Internet addiction and its correlates and among high school student : A. Preliminary study from ahmedabad India" in Asian Journal of Psychiatry (2013), http://dx.org/10.1016/j.ajp.2013.06.004(2013)

[10] Pontes HM, Griffiths MD and Patrao IM: Internet Addiction and LonelinessAmongChildren and Adolescents ini Education Setting An Empirical Pilot Study in InternationalGaming Research Unit, Psychology Division, Nottingham Trent University, 32(1), 91-98(2014)

[11] Jovic J., Dindic N.: Influence of Dopaminergic System on Internet Addiction retrievedhttp://publisher.medfak.in.ac.rs//2011-html/i.broj/jelena\%20 jovic influence of dopaminergic pdf (2011)

[12] Hou H. et al.: Research Article : Reduced Striatal Dopamine Transporter in People with Internet Addiction Disorder in Journal of Biomedicine and Biotechnology Vol 2012.Article ID 854524 (2012)

[13] Hahn C., Kim DJ.: Is there a shared neurobiology between aggression and Internet Addiction disorder? in Journal of Behavioral Addiction 3(1), pp:12-20(2014)

[14] Young KS., Tue XD.,Ying L.: Prevalence Estimates and Etiologic Models of Internet Addiction in Internet Addiction A Handbook and Guide to Evaluation and Treatment edited by Kimberly S. Young and Cristiano Nabuco de Abreu, John Wiley \& Sons, Hoboken, New Jersey (2011) 